\title{
Cardiac magnetic resonance imaging (CMR) characteristics in apical versus non-apical hypertrophic cardiomyopathy (HCM)
}

\author{
Amardeep Ghosh Dastidar*, Priyanka Singhal, Giuseppe Venuti, Antonio Matteo Amadu, Anna Baritussio, \\ Alessandra Scatteia, Estefania De Garate, Chris B Lawton, Jonathan C Rodrigues, Chiara Bucciarelli-Ducci
}

From 19th Annual SCMR Scientific Sessions

Los Angeles, CA, USA. 27-30 January 2016

\section{Background}

Hypertrophic cardiomyopathy (HCM) is the most common genetic cardiac disorder, and the most common cause of sudden cardiac death (SCD) in young adults. The 3 main phenotypes are asymmetric, concentric or apical, with asymmetric being the most common. Literature suggests apical HCM to be a rare variant (variable prevalence) with better prognosis but the data is limited.

\section{Aims}

Provide a contemporary prevalence and characteristics of apical HCM in a large tertiary clinical CMR service.

\section{Methods}

Approximately 3,100 CMR scans were reviewed from our CMR registry (Jan 2014 to Mar 2015). comprehensive CMR protocol was used including cines, early and late gadolinium enhancement imaging. 114 consecutive HCM patients were identified. A Asymmetric HCM was defined as: septal to free wall thickness ratio of $>1.3$; apical HCM as apical wall thickness of $>15 \mathrm{~mm}$ or apical to basal LV wall thicknesses $\geq 1.3-1.5$; and concentric HCM as symmetrical hypertrophy of ventricular wall without any regional preferences. Non-apical HCM group (comprising of asymmetric and concentric phenotypes) were compared with apical HCM. Fisher's exact $t$-test and unpaired t-test were performed for statistical significance. P-value $<0.05$ was statistically significant. Univariate and multivariate logistic regression analyses were performed to determine the CMR predictors of apical HCM.

\section{Results}

The final study sample consisted of 104 patients with HCM with median age 60years (IQR $=54-70)$ and $70 \%$ male, (10 patients excluded due to uncertain diagnosis) $70 \%$ non-apical HCM; the remainder 30\% apical HCM. In the non-apical HCM group, 5 patients had concentric HCM and the rest had asymmetric HCM. The. The mean maximum LV wall thickness, mean indexed LV mass, mean indexed stroke volume, prevalence of LVOTO and SAM were significantly greater in nonapical group. Table 1 The presence of LGE was high in both groups $(>85 \%)$ and was not statistically different. The univariate predictors of apical HCM included maximum LV wall thickness, indexed stroke volume, LVOT obstruction whereas in the multivariate model maximum LV wall thickness remained the only significant predictor.

\section{Conclusions}

Our study suggests that in the era of CMR, the prevalence of apical HCM to be almost $1 / 3^{\text {rd }}$ of all observed HCM cases. The study also demonstrates that the prevalence of LGE was high also in the apical HCM group suggesting that the better prognosis that apical HCM is thought to have based on the absence of myocardial fibrosis should be reconsidered. Further large prospective multi-centre trials are needed to establish the key differences thereby understanding the pathophysiology. 
Table 1 CMR characteristics of Apical vs non-Apical HCM

\begin{tabular}{|c|c|c|c|c|}
\hline CMR findings: & Total Cohort $(n=104)$ & Non-apical $(n=73)$ & Apical $(n=31)$ & P-value \\
\hline Mean LVEF (\%) & 69.7 & 68.4 & 72.6 & 0.0552 \\
\hline Mean LVEDVI (mL m-2) & 73.7 & 76.7 & 66.8 & 0.0718 \\
\hline Mean LVESVI (mL m-2) & 23.8 & 25.5 & 20.1 & 0.1177 \\
\hline Mean indexed stroke volume & 53.1 & 55.9 & 46.4 & 0.0333 \\
\hline Mean max. LV wall thickness (mm) & 18.2 & 19.3 & 15.6 & 0.0001 \\
\hline Mean indexed LV mass & 93.5 & 98.4 & 82.4 & 0.0102 \\
\hline LVOTO & 35.2 & 41.1 & 12.5 & 0.0403 \\
\hline SAM & 31.4 & 38.9 & 6.25 & 0.0143 \\
\hline LGE \% & 86.9 & 85.7 & 89.7 & 0.8063 \\
\hline
\end{tabular}

LVEF, left ventricular ejection fraction; LVEDVI, left ventricular end diastolic volume index; LVESVI, left ventricular end systolic volume index; LVOTO, Left ventricular outflow tract obstruction; SAM, systolic anterior valve motion; LGE, late gadolinium enhancement.

Published: 27 January 2016

doi:10.1186/1532-429X-18-S1-P269

Cite this article as: Dastidar et al:: Cardiac magnetic resonance imaging

(CMR) characteristics in apical versus non-apical hypertrophic

cardiomyopathy (HCM). Journal of Cardiovascular Magnetic Resonance

2016 18(Suppl 1):P269.

Submit your next manuscript to BioMed Central and take full advantage of:

- Convenient online submission

- Thorough peer review

- No space constraints or color figure charges

- Immediate publication on acceptance

- Inclusion in PubMed, CAS, Scopus and Google Scholar

- Research which is freely available for redistribution

Submit your manuscript at www.biomedcentral.com/submit 